\title{
Keterkaitan Variasi Sinar Kosmik dengan Tutupan Awan
}

\author{
Riza Adriat1)
}

\author{
1)Fakultas Ilmu dan Teknologi Kebumian, Institut Teknologi Bandung \\ Email: rizaadriat@gmail.com
}

\begin{abstract}
Abstrak
Sinar kosmik merupakan salah satu faktor dari luar angkasa yang mempengaruhi pemanasan global melalui pengaruhnya terhadap proses pembentukan tutupan awan. Sinar kosmik dapat mempengaruhi proses pembentukan tutupan awan melalui mekanisme ion-aerosol clear-air dan mekanisme ion-aerosol near-cloud. Sinar kosmik berperan sebagai sumber energi yang mengionisasi aerosol sehingga mempercepat pembentukan inti kondensasi awan. Sinar kosmik dikorelasikan dengan awan global menggunakan klasifikasi ISCCP yang membagi awan menjadi sembilan jenis dari tahun 1984 sampai 2008. Sinar kosmik memiliki korelasi positif dengan tutupan awan rendah (untuk jenis Stratocumulus dan Stratus) dan tutupan awan tinggi (untuk jenis Cirrus).
\end{abstract}

Kata kunci: pemanasan global, sinar kosmik, tutupan awan

\section{Latar belakang}

Perubahan iklim dipengaruhi oleh dua faktor utama, pengaruh antropogenik dan alami (IPCC, 2013). Faktor yang paling besar dalam perubahan iklim dipengaruhi oleh pemanasan global. Pemanasan global disebabkan oleh gas rumah kaca yang dipengaruhi oleh peningkatan emisi $\mathrm{CO}_{2}$, di mana aktivitas antropogenik menjadi penyebab utama peningkatan emisi $\mathrm{CO}_{2}$ tersebut. Selain itu, faktor alami yang mempengaruhi perubahan iklim adalah aktivitas matahari yang dapat mempengaruhi tiga unsur, yaitu perubahan laju pemanasan atmosfer, aktivitas magnetik, dan sinar kosmik (Carslaw dkk., 2002). Berdasarkan hasil kajian sebelumnya oleh Svensmark dan FrissChristensen (1997), menunjukkan bahwa terdapat potensi pengaruh radiasi sinar kosmik terhadap perubahan iklim.

Sinar kosmik adalah radiasi yang berasal dari ledakan bintang (supernova) dan biasa disebut Galactic Cosmic Rays. Perambatan sinar kosmik menuju bumi dipengaruhi oleh aktivitas matahari, jumlah bintik matahari, dan angin matahari (Dickinson, 1975). Peningkatan (penurunan) intensitas ketiga faktor tersebut akan menurunkan (meningkatkan) intensitas radiasi sinar kosmik yang menuju bumi. Radiasi sinar kosmik yang mencapai bumi dapat mempengaruhi pemanasan global melalui pembentukan tutupan awan (Svensmark dan Friss-Christensen, 1997).

Sinar kosmik mempengaruhi proses pertumbuhan awan berdasarkan mekanisme ion-aerosol clear-air (Yu, 2002) dan ion-aerosol near-cloud (Carslaw dkk., 2002) melalui ionisasi aerosol oleh sinar kosmik yang mengakibatkan percepatan pembentukan inti kondensasi awan. Hasil kajian Marsh dan Svensmark (2000) menyimpulkan bahwa sinar kosmik mempengaruhi proses pertumbuhan awan rendah (1000 mb hingga $680 \mathrm{mb})$ yang ditunjukkan oleh korelasi positif antara sinar kosmik terhadap tutupan awan rendah (Gambar 1). Awan rendah sangat dipengaruhi oleh distribusi aerosol sehingga jika terjadi peningkatan sinar kosmik, pembentukan inti kondensasi awan rendah akan mengalami percepatan. Penelitian ini akan mengkaji lebih lanjut mengenai keterkaitan radiasi sinar kosmik terhadap tutupan awan untuk periode waktu yang lebih panjang dibandingkan dengan penelitian sebelumnya (1984-2008).
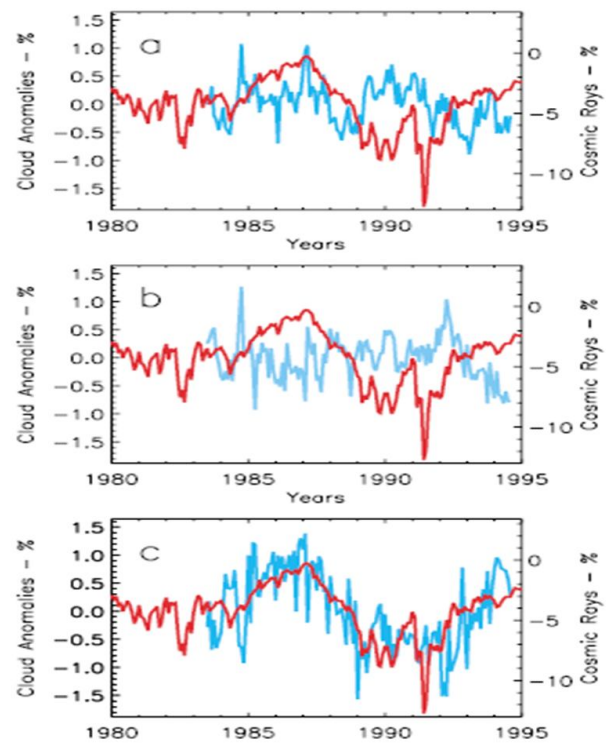

Gambar 1. Rata-rata global anomali tutupan awan bulanan untuk (a) tinggi ( $<440$ hPa), (b) tengah (440-680 hPa), dan (c) rendah (>680 hPa) tutupan awan (biru) dan sinar kosmik (merah). (Marsh dan Svensmark, 2000) 


\section{Metodologi}

i. Data

Data yang digunakan dalam penelitian ini adalah data sinar kosmik dan tutupan awan.

a. Sinar Kosmik

Data sinar kosmik yang digunakan dalam penelitian ini adalah data bulanan dalam periode tahun 1984-2008 dari stasiun Huancayo, Peru $\left(12^{\circ} \mathrm{LS}, 75^{\circ} \mathrm{BB}\right)$ karena stasiun ini letaknya paling dekat dengan ekuator sehingga radiasi sinar kosmiknya tidak dipengaruhi gangguan lain, seperti medan magnet kutub bumi.

b. Tutupan Awan

Data tutupan awan yang diperoleh dari International Satellite Coud Climatology Project (ISCCP) tahun 1984-2008. Data ISCCP merupakan data tutupan sembilan jenis awan yang dibedakan berdasarkan ketinggian dan ketebalan optiknya. Awan rendah memiliki ketinggian antara $1000 \mathrm{mb}$ hingga $680 \mathrm{mb}$, awan menengah memiliki ketinggian $680 \mathrm{mb}$ hingga $440 \mathrm{mb}$, dan awan tinggi memiliki ketinggian antara 440 hingga $50 \mathrm{mb}$. Hal ini terlihat pada klasifikasi awan yang ditunjukkan Gambar 2.

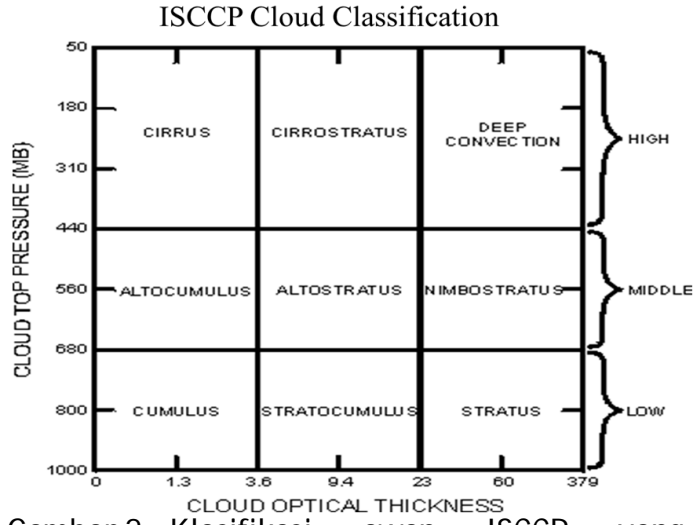

Gambar 2. Klasifikasi awan ISCCP yang dibedakan berdasarkan ketinggian dan ketebalan optik awan (Rossow dan Schiffer, 1999).

\section{ii. Metode}

Metode yang digunakan adalah desktriptif analitis. Langkah-langkah penelitian yang dilakukan meliputi persiapan dan pengolahan data.

\section{a. Perata-rataan Data}

Proses perata-rataan data dilakukan dengan menggunakan Persamaan (1)

$$
S_{j}(x, y)=\frac{1}{12} \sum_{1}^{i+12} M_{i}(x, y)
$$

$S_{j}(x, y)$ adalah variabel pada tahun ke-j (j=1,...25), dan $M_{i}(x, y)$ adalah variabel terpilih pada bulan ke-i $(\mathrm{i}=1, \ldots, 12)$. Dengan demikian, didapatkan pengelompokan rata-rata tahunan dari tutupan awan dan sinar kosmik.

\section{b. Anomali Data}

Proses konversi data menjadi anomali dilakukan dengan mengurangi data dengan ratarata data melalui Persamaan (2)

$$
S^{\prime}(x, y)=S(x, y)-\bar{S}(x, y)
$$

$S^{\prime}(x, y)$ adalah anomali data, $S(x, y)$ adalah data dan $\bar{S}(x, y)$ adalah rata-rata data.

\section{c. Ekstraksi Pola Spasial dan Temporal Tutupan Awan}

Korelasi spasial antara sinar kosmik dan tutupan awan diperoleh dengan cara mengorelasikan data tutupan awan di setiap grid dengan data sinar kosmik di stasiun yang diasumsikan seragam secara global, sedangkan korelasi temporalnya diperoleh dengan cara merata-ratakan secara global hasil dari korelasi spasial antara sinar kosmik dan tutupan awan.

\section{Hasil dan Pembahasan}

i. Korelasi Spasial dan Temporal Tutupan Awan Rendah dengan Sinar Kosmik

Pola spasial dan temporal antara sinar kosmik dan tutupan awan menunjukkan bahwa sinar kosmik berkorelasi positif dengan awan rendah untuk jenis Stratocumulus dan Stratus seperti ditunjukkan pada Gambar 3. 
a.

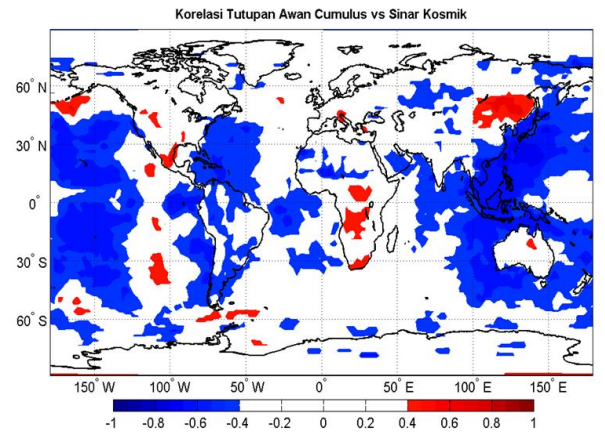

b.

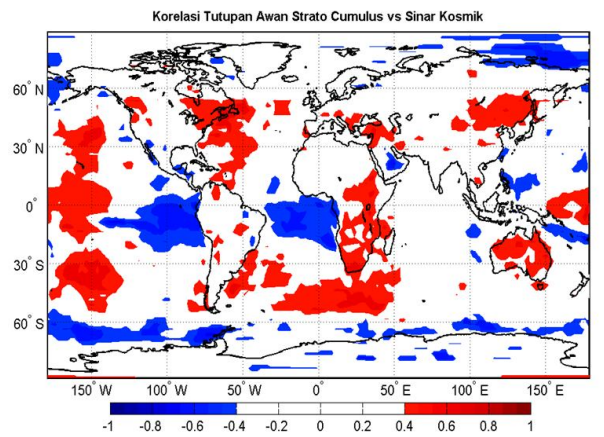

C.

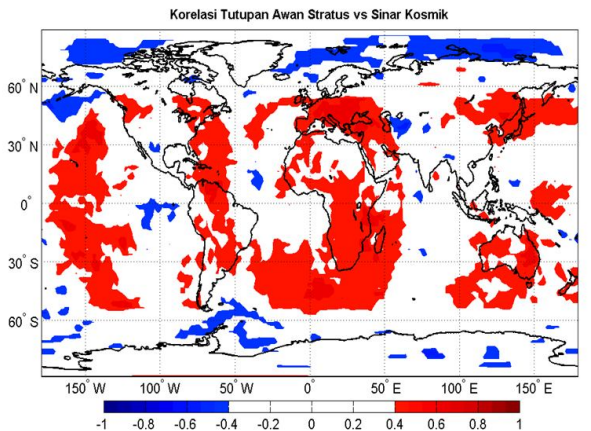

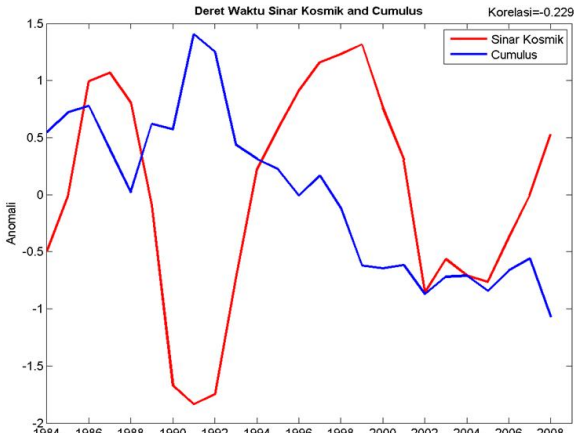

$\begin{array}{lllllllllllll}-2 & 1984 & 1 & 1 & 1 & 1 & 1 & 1 & 1 & 1 & 1 & 1 & 1 \\ 1988 & 1990 & 1992 & 1994 & 1996 & 1998 & 2000 & 2002 & 2004 & 2006 & 2008\end{array}$
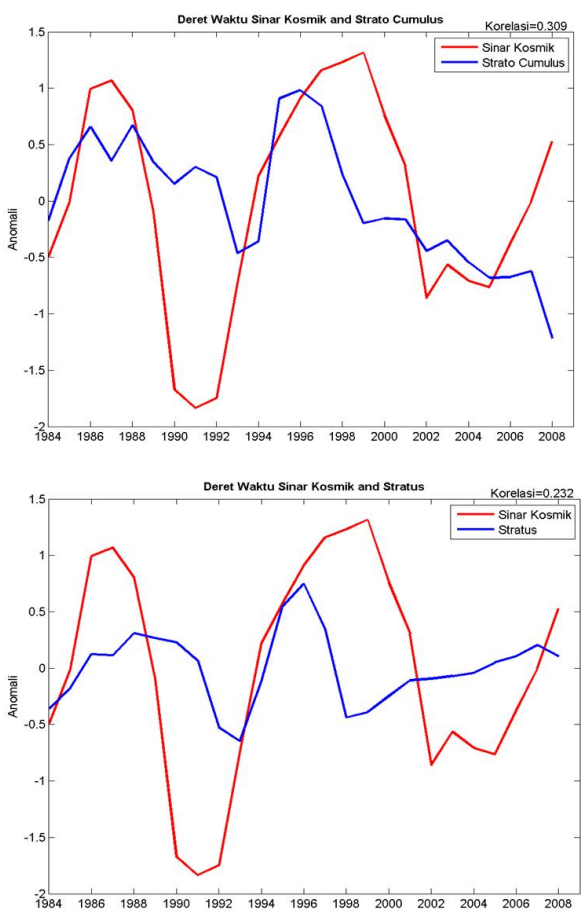

Gambar 3. Korelasi spasial (panel kiri) dan korelasi temporal (panel kanan) antara sinar kosmik dan tutupan awan rendah di mana korelasi temporal antara sinar kosmik dan (a) Cumulus, (b) Stratocumulus, (c) Stratus berturut-turut adalah -0,229; 0,309; dan 0,232.

Berdasarkan Gambar 3 terlihat bahwa tutupan awan jenis Stratocumulus dan Stratus paling dipengaruhi oleh sinar kosmik karena korelasi spasialnya menunjukkan banyak daerah yang berkorelasi positif dan korelasi temporalnya di atas 0,2 (Gambar 3b dan Gambar 3c). Namun untuk tutupan awan jenis Cumulus banyak daerah yang berkorelasi negatif dan korelasi temporalnya juga bernilai negatif (Gambar 3a). Korelasi temporal antara sinar kosmik dan tutupan awan rendah untuk jenis Cumulus, Stratocumulus, dan Stratus berturutturut adalah -0,229; 0,309; dan 0,232.

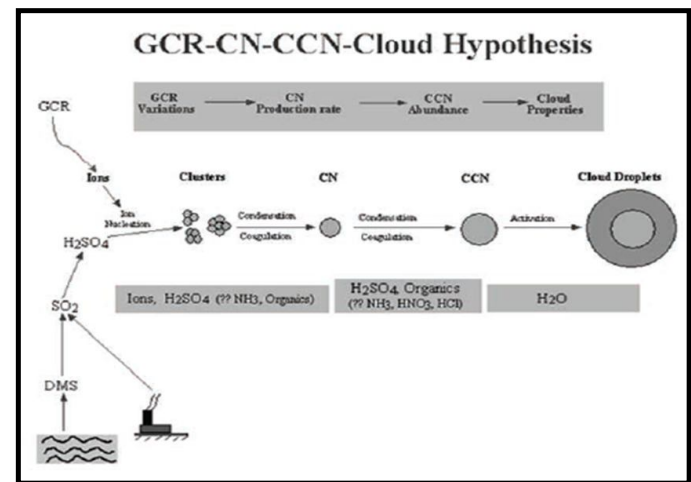

Gambar 4. Mekanisme ion-aerosol clear-air, hubungan antara sinar kosmik, CN, CCN, dan awan (Yu, 2002).

Hal ini terkait dengan mekanisme ion aerosol-clear air (Gambar 4) yang dikemukakan 
oleh Yu (2002) bahwa awan rendah sangat sensitif terhadap distribusi aerosol. Jika terjadi peningkatan sinar kosmik, radiasi sinar kosmik akan menyebabkan meningkatnya laju ionisasi aerosol dalam pembentukkan inti kondensasi awan rendah yang menyebabkan semakin banyak proses pembentukan awan rendah.

\section{ii. Korelasi Spasial dan Temporal Tutupan Awan Menengah dengan Sinar Kosmik}

Berbeda dengan jenis awan rendah, seluruh jenis awan menengah tidak memiliki korelasi dan berkorelasi negatif dengan sinar kosmik baik secara spasial maupun temporalnya. Gambar 5 menunjukkan korelasi spasial dan

a.

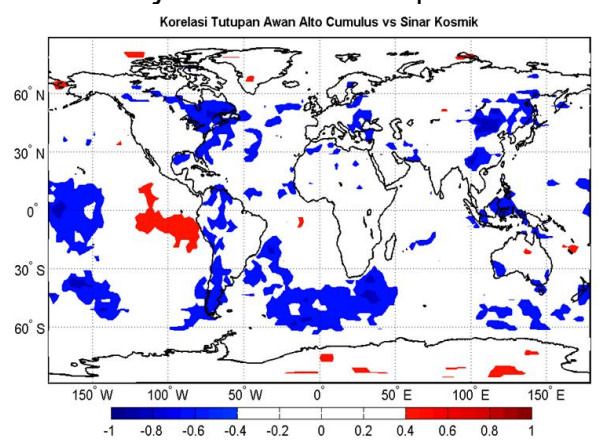

b.

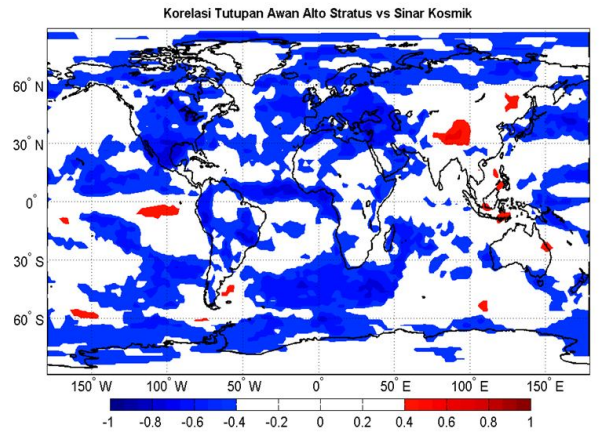

C.

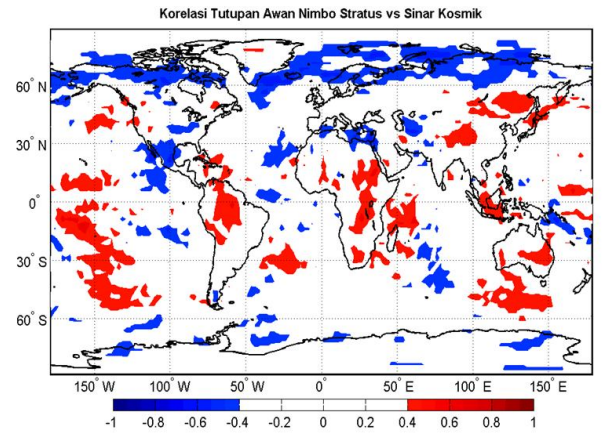

temporal antara sinar kosmik dan tutupan awan menengah untuk jenis Altocumulus, Altostratus, dan Nimbostratus di mana korelasi temporalnya berturut-turut adalah -0,519; -0,296; dan 0,047. Awan menengah jenis Altocumulus memiliki korelasi negatif yang tinggi yaitu $-0,519$, yang berarti awan menengah jenis Altocumulus pembentukannya lebih disebabkan proses konvektif dari efek termal radiasi matahari. Pengaruh ionisasi sinar kosmik terhadap tutupan awan menengah tidak dominan, karena pembentukan tutupan awan menengah lebih banyak disebabkan dinamika termal atmosfer seperti hantaran energi secara konduksi.
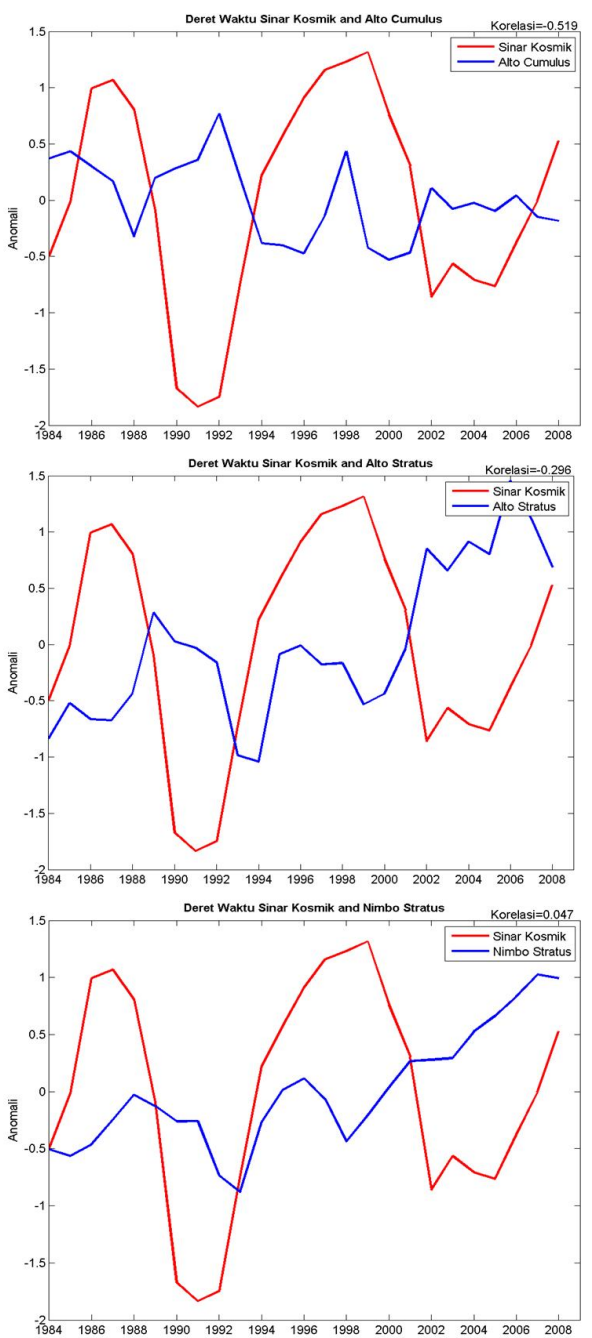

Gambar 5. Korelasi spasial (panel kiri) dan korelasi temporal (panel kanan) antara sinar kosmik dan tutupan awan menengah di mana korelasi temporal antara sinar kosmik dan (a) Altocumulus, (b) Altostratus, (c) Nimbostratus berturut-turut adalah -0,519; -0,296; dan 0,047. 


\section{iii. Korelasi Spasial dan Temporal Tutupan Awan Tinggi dengan Sinar Kosmik}

Hasil korelasi sinar kosmik dengan awan tinggi menunjukkan bahwa tutupan awan jenis Cirrus memiliki korelasi positif paling tinggi jika dibandingkan dengan jenis tutupan awan lainnya seperti ditunjukkan pada Gambar 6a. Nilai korelasi temporal antara sinar kosmik dan tutupan awan tinggi untuk jenis Cirrus, Cirrostratus, dan Deep-Convection berturut-turut adalah 0,354; -0,463; dan 0,167 (Gambar 6).

Korelasi positif antara sinar kosmik dan awan tinggi untuk jenis Cirrus kemungkinan juga disebabkan oleh mekanisme ion aerosolclear air dan mekanisme tambahan yaitu mekanisme ion aerosol-near cloud (Gambar 7). Mekanisme ini diusulkan oleh Carslaw (2002) karena gangguan yang terjadi di atas awan.

a.

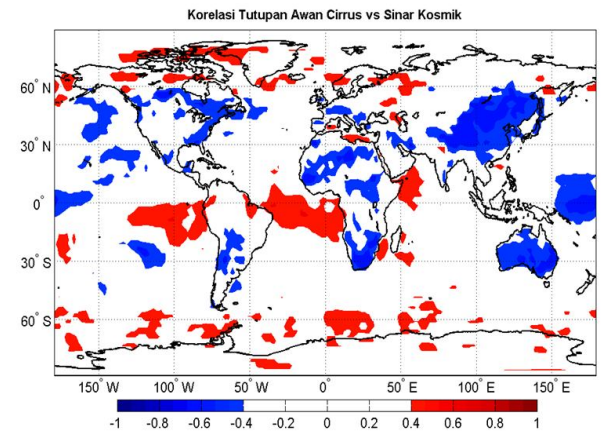

b.

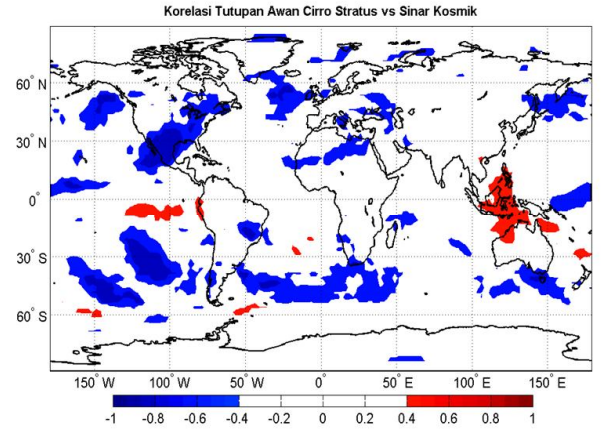

C.

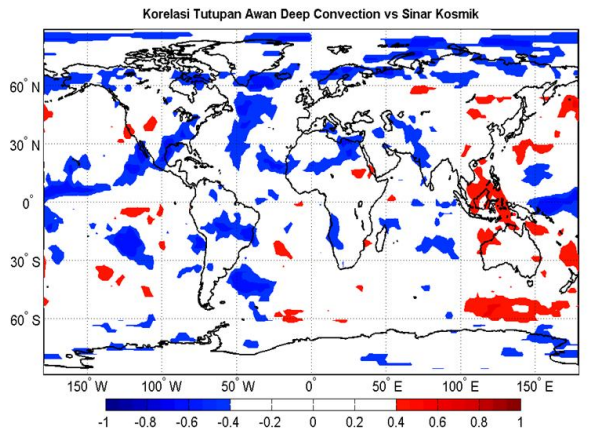

Daerah di sekitar 200 meter di atas lapisan awan yang tipis menjadi lebih bermuatan positif daripada udara di sekitarnya karena ionisasi sinar kosmik. Kemudian partikel-partikel proton tersebut mengionisasi aerosol yang ada di atas lapisan awan dan mengalami scavenging ke dalam awan. Tinsley (2003) juga mengusulkan bahwa ionisasi dan scavenging menyebabkan meningkatnya keberhasilan aerosol sebagai inti pembentuk es. Sementara proses pembentukan untuk awan tinggi jenis Cirrostratus dan DeepConvection lebih disebabkan karena dinamika atmosfer seperti proses konvektif dari radiasi matahari karena terlihat dari korelasi temporalnya untuk awan tinggi jenis Cirrostratus memiliki korelasi negatif yang tinggi yaitu -0,463.
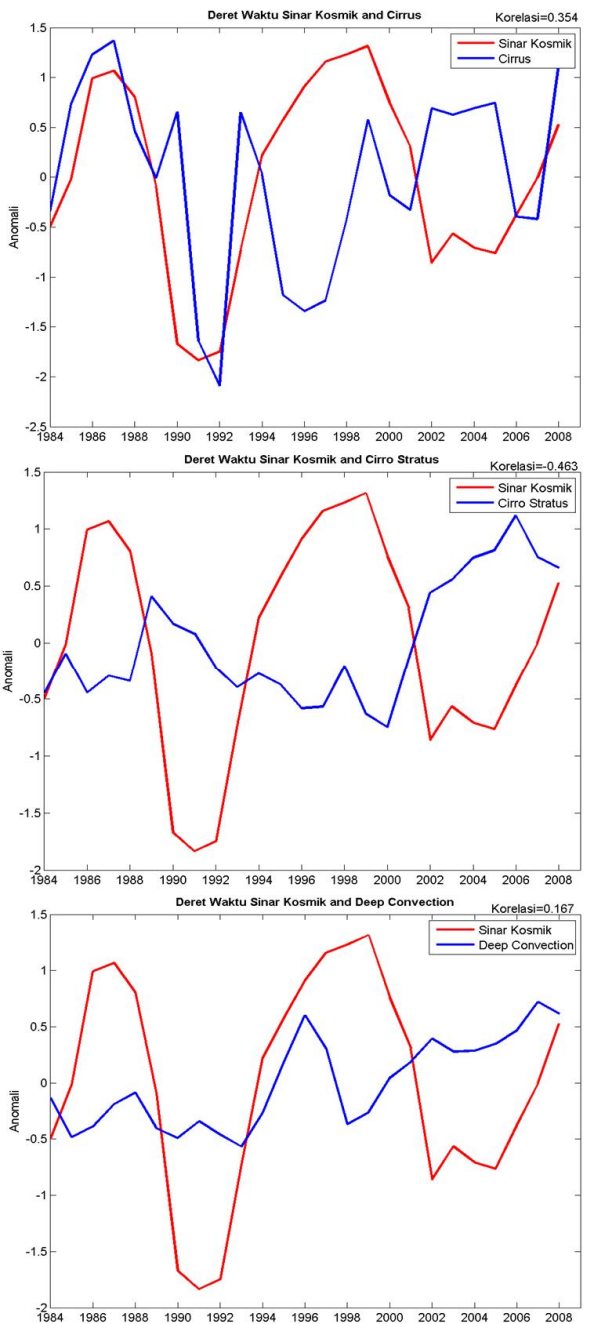

Gambar 6. Korelasi spasial (panel kiri) dan korelasi temporal (panel kanan) antara sinar kosmik dan tutupan awan tinggi di mana korelasi temporal antara sinar kosmik dan (a) Cirrus, (b) Cirrostratus, (c) Deep-Convection berturut-turut adalah 0,354; -0,463; dan 0,167. 


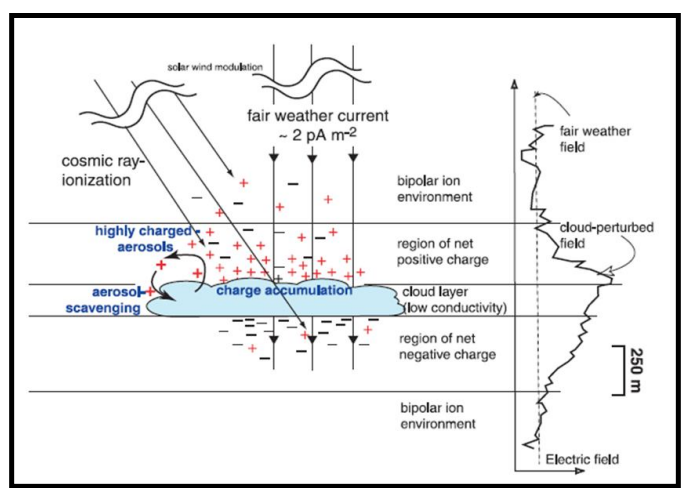

Gambar 7. Mekanisme ion-aerosol near-cloud ketika partikel sinar kosmik berkumpul di atas lapisan awan yang tipis kemudian mengalami scavenging sehingga akan meningkatkan kesempatan aerosolaerosol di dalam awan menjadi inti pembentuk es (Carslaw dkk., 2002).

Berdasarkan hasil korelasi temporal untuk seluruh jenis awan dengan sinar kosmik diperoleh awan jenis Stratocumulus, Stratus, dan Cirrus yang memiliki korelasi positif tertinggi. Ketiga jenis awan ini proses pembentukkannya paling dipengaruhi oleh sinar kosmik. Secara temporal ketiga jenis awan di atas akan memiliki anti korelasi dengan siklus aktivitas bintik matahari. Sebaliknya awan jenis Altocumulus dan Cirrostratus memiliki korelasi negatif tertinggi dengan sinar kosmik. Jenis awan ini pembentukannya lebih dominan dipengaruhi oleh dinamika atmosfer dan korelasi kedua jenis awan ini akan beriringan dengan fase siklus aktivitas bintik matahari. Untuk lebih jelasnya hasil korelasi temporal antara tutupan awan dan sinar kosmik ditunjukkan oleh Tabel 1.

Tabel 1. Korelasi temporal tutupan awan dan sinar kosmik.

\begin{tabular}{cc}
\hline Jenis Awan & Korelasi Temporal \\
\hline Cumulus & $-0,229$ \\
Stratocumulus & 0,309 \\
Stratus & 0,232 \\
Altocumulus & $-0,519$ \\
Nimbostratus & 0,047 \\
Cirrus & 0,354 \\
Cirrostratus & $-0,463$ \\
Deep-Convection & 0,167 \\
\hline
\end{tabular}

\section{Kesimpulan}

Secara global, variasi sinar kosmik mempunyai korelasi positif dengan fraksi tutupan awan rendah jenis Stratocumulus dan Stratus, serta awan tinggi jenis Cirrus dalam periode 1984 sampai tahun 2000. Hasil ini konsisten dengan temuan Marsh dan Svensmark (2000) yang menggunakan data dari tahun 1984 sampai 1995. Selebihnya, kajian ini mengungkapkan bahwa nilai korelasi positif yang tinggi antara sinar kosmik dengan tutupan awan hanya berlaku di wilayah yang fraksi tutupan awannya secara rata-rata rendah (kurang dari 10\%), di mana pengaruh dinamika atmosfer lokal dalam proses pembentukan awan dapat dianggap cukup lemah sehingga sinar kosmik dapat secara efektif mempercepat dan memperbanyak proses pembentukan inti kondensasi awan.

\section{Daftar Pustaka}

Carslaw, K.S., Harrison, R.G., dan Kirkby, J. (2002) : Cosmic rays, clouds, and climate, Science, 298, 1732-1737.

Dickinson, R.E. (1975) : Solar variability and the lower atmosphere, Bull. Amer. Meteor. Soc., 56, 1250-1248.

IPCC. (2013) : Anthropogenic and Natural Radiative Forcing, IPCC WGI Fifth Assessment Report , Chapter 8, 659-740.

Marsh, N.D. dan Svensmark, H. (2000) : Low cloud properties influenced by cosmic rays, Phys. Rev. Lett., 85, 5004-5007.

Rossow, W.B. dan Schiffer, R.A. (1999) : Advances in understanding clouds from ISCCP, Bull. Amer. Meteor. Soc, 80, 22612287.

Svensmark, H. dan Friss-Christensen, E. (1997) : Variation of cosmic ray flux and global cloud coverage-a missing link in solarclimate relationship, J. Atmos. Solar-Terr. Phys, 59, 1225-1232.

Yu, F. (2002) : Altitude variations of cosmic ray induced production of aerosol: Implication for global cloudiness and climate, Geophys. Res. Lett, 107, 1-10. 